\title{
LA RETROTRADUCCIÓN DE LA LITERATURA CHINOAMERICANA A LA CULTURA CHINA: ANÁLISIS COMPARATIVO DE LAS VERSIONES CHINAS DE THE JOY LUCK CLUB DE AMY TAN Chenying $W$ ang \\ Universidad de Asuntos Exteriores de China
}

\section{ABSTRACT}

Amy Tan, a representative author of the Chinese American Literature, succeeded in displaying the wonderful world in which the in-between beings live to the Chinese public. In this article, we will study the back-translation of The Joy Luck Club, Amy Tan's the most successful novel, to the Chinese culture. By comparing its three Chinese versions, we will analyze the different translational strategies adopted by different translators: either to maintain the distinctiveness of the Chinese American culture in order to make the Chinese readers realize the difference between the traditional Chinese culture and the Chinese American culture or to preserve the purity of Chinese traditional culture, by deleting o correcting the information that isn't in conformity with it.

KEY WORDS: back-translation, Chinese American Literature, Amy Tan, domestication, foreignization.

\section{RESUMEN}

Amy Tan, autora representativa de la literatura chinoamericana, logró abrir al público chino la puerta que conduce al mundo maravilloso en que viven los seres in-between. En este trabajo, estudiaremos la retrotraducción a la cultura china de The Joy Luck Club, novela más exitosa de la misma autora, comparando sus tres versiones chinas con el fin de analizar las distintas estrategias traslativas que adoptan las traductoras: mantener lo distintivo de la cultura chinoamericana con el fin de hacer a los lectores chinos tener en cuenta la diferencia que existe entre la cultura chinoamericana y la china o preservar la pureza de la cultura china, omitiendo o corrigiendo lo que no le parece "auténtico" a la traductora desde un punto de vista tradicional china.

PALABRAS CLAVE: retrotraducción, literatura chinoamericana, Amy Tan, domesticación, exotización.

FECHA DE RECEPCIÓN: 30/09/2014

FECHA DE ACEPTACIÓN: 25/03/2015

PÁGINAS: 67-91 


\section{INTRODUCCIÓN}

Amy Tan, figura representativa de la literatura chinoamericana, no sólo logró que esta corriente literaria volviera a brillaren el mundo occidental, sino que también abrió al público chino la puerta que conduce al mundo maravilloso en que viven los seres in-between. A través de la retrotraducción de su primera novela, The Joy Luck Club, la audiencia china empezó a darse cuenta de la diversidad de la chinidad (Chineseness). En esta obra postcolonial, la invención de ciertos términos culturales, costumbres, alusiones intertextuales o tradiciones mitológicas que acarrean la identidad cultural o la configuración ideológica de la autora constituye una de las principales técnicas creativas que, por un lado, fascinan a los lectores y por otro, traen dificultades a los traductores chinos en el proceso de la retrotraducción.

En este trabajo, estudiaremos tres versiones chinas de esta obra, analizando las distintas estrategias traslativas que adoptan las traductoras y retomaremos el dilema eternoal que los traductores han de enfrentarse: cla exotización o la domesticación? En España, The Joy Luck Club tiene dos traducciones castellanas realizadas por distintos traductores, las cuales fueron reeditadas 16 veces en España durante 20 años (1990-2009). Con interés adyacente, cotejaremos la versión castellana realizada por Jordi Fibla desde una perspectiva transcultural para revelar ciertos fenómenos que se producen en la "retrotraducción" y se ignoran en el proceso de la transmisión interlingüística.

\section{LAS TRES VERSIONES CHINAS DE THE JOY LUCK CLUB Y SUS TRADUCTORAS}

Desde que se publicó The Joy Luck Club (1989), han aparecido sucesivamente cinco versiones chinas completas, entre las cuales cuatro son de la China continental y una de Taiwán, lo que no ha ocurrido con ninguna otra obra chinoamericana. La primera versión se publicó en 1990 por la editorial Unitas de Taiwán, traducida por Renrui Yu. Dos años después aparecieron otras tres versiones chinas sucesivamente: la versión de Qing Tian, que se publicó en la editorial Chunfeng Wenyi, la versión de Naishan Cheng y otros, publicada por la editorial Zhejiang Wenyi, y la versión de Haiping Wu y otros, publicada por la editorial Anhui Wenyi; la última edición se realiza también por parte de Cheng y otros, pero es una traducción casi totalmente diferente de su versión de 1992, publicada por la editorial Shanghai Translation Publishing House en 2006. En este trabajo, sólo nos centraremos en tres versiones chinas: la versión de Tian, la de Yu y la última versión de Cheng y otros. Al analizar estas tres versiones, veremos que Tian y Yu intentan mantener lo distintivo de 
la cultura chinoamericana y, al contrario, Cheng se inclina a preservar la pureza de la cultura china, omitiendo o reescribiendo lo que no le parece "auténtico". En la versión de Tian, se mantienen en el texto traducido las transcripciones fonéticas del chino y el pinyin romanizado con el fin de destacar la cultura chinoamericana y hacer tomar conciencia a los lectores chinos de la diferencia que existe entre la cultura chinoamericana y la china; en la versión de $\mathrm{Yu}$, a pesar de que la traductora elimine las transcripciones fonéticas y el pinyin romanizado, intenta mantener las características de la cultura chinoamericana respetando la intención creativa de la autora.

Igual que los escritores, los traductores no son nunca inocentes ni tampoco pueden ser neutros ni estar completamente libres de las influencias que ejercen las fuerzas políticas, institucionales e ideológicas de la sociedad donde se encuentran. En este sentido, conocer las circunstancias donde viven los traductores y su formación y trayectoria personal es de gran ayuda a la hora de estudiar con profundidad los factores poéticos e ideológicos que condicionan o determinan la elección de las estrategias traslativas en el proceso de traducción.

Renrui Yu, taiwanesa y profesora de la Universidad de Ohio (Estados Unidos), es experta en literatura anglo-americana y especialista en estudios comparativos de las obras dramáticas de Shakespeare. Aparte de The Joy Luck Club, también ha traducido ciertas obras de Freud. Naishan Cheng es autora famosa que forma parte de la "escuela shanghainesa". Su versión, en la que se introducen muchas expresiones del dialecto shanghainés, está fuertemente marcada por un "sabor shanghainés". Quizá la diferencia en la adscripción profesional determina la elección de sus diferentes actitudes hacia la cultura chinoamericana y la china. Yu, estudiosa de la literatura anglo-americana, está más cerca de la cultura chinoamericana; al contrario, Cheng, autora china, se siente más responsable de mantener la autoridad y la autenticidad de la cultura china. Acerca de Tian, desafortunadamente, no hemos localizado mucha información. Sin embargo, desde la actitud que mantiene hacia la cultura chinoamericana, se percibe un alto conocimiento de la cultura anglo-americana. Por todo lo que hemos visto, notamos que las circunstancias donde se hallan los traductores y su formación académica y profesional desempeñan un papel de suma importancia a la hora de seleccionar las estrategias traductoras. En el siguiente apartado de este trabajo, estudiaremos con detenimiento algunos casos concretos que complican o dificultan la actividad traslativa. 
3. IMPLICACIONES EN LA RETROTRADUCCIÓN DE THE JOY LUCK CLUB

\subsection{LA TRADUCCIÓN DE LAS ONOMATOPEYAS}

La oralidad constituye una de las características más destacadas de las obras de Amy Tan. Según la autora, son las historias relatadas por su madre y su abuela las que alimentan su inspiración creativa. De hecho, Amy Tan considera a su madre como la "musa" de su creación:

I say the muse is my mother, the woman who gave me both my DNA and certain ideas about the world. Or I pay homage to my grandmother and say that it is she who inspired me to find my voice because she had lost hers so irrevocably (Tan 2003: 250).

Desde pequeña, Amy Tan escucha las historias que narraba su madre y hereda de ella la fuerte tradición oral del story-telling. En su libro, la autora aprovecha muchas técnicas narrativas tradicionales chinas que dan forma a una lengua expresiva, que es capaz de describir vivamente las características de los diferentes personajes inmigrantes y sus movimientos interiores. En otras palabras, la autora trasplanta las tradiciones narrativas orales chinas al inglés. Una de las principales técnicas que la autora adopta es el uso de las onomatopeyas.

Las onomatopeyas son la imitación o la recreación fonética de los sonidos de los fenómenos naturales, de los ruidos que producen los animales o de otras acciones no discursivas. En la creación literaria, las onomatopeyas constituyen un recurso potencial que es capaz de llevar al lector al tiempo y al lugar en que tuvo lugar un suceso o de hacer que la imagen vívida de una figura venga a la mente del lector, etc. Hay que destacar que cada cultura tiene su propio sistema de onomatopeyas. En los casos extremos, los diferentes sistemas lingüísticos no comparten ninguna similitud al respecto. Por ejemplo, en español, la onomatopeya que imita el sonido de llamar a la puerta sería "pon pon" o "toc toc", en inglés, "knock knock." y en chino, "dong dong”. Aunque, si estas onomatopeyas se eliminan, el significado del texto no se ve afectado, constituyen una de las marcas más notables de un sistema lingüístico o de una cultura; es más, en los textos postcoloniales pueden ser la marca de cierta identidad especial.

En sus obras Amy Tan introduce muchas onomatopeyas del chino provenientes de las madres, transcritas por la autora con el pinyin romanizado. Sin embargo, como la autora no tiene la experiencia de vivir en China, en muchas ocasiones las onomatopeyas son "imitaciones" de lo que ha oído a su 
alrededor o son "invenciones" de su imaginación. Estas onomatopeyas "chinas" que no existen en el sistema lingüístico del chino mandarín complican la retrotraducción. A continuación veremos algunos ejemplos:

I remember them because one lady made watery "shrrhh, shrrhh" sounds. When I was older, I came to recognize this as Peking accent, which sounds quite strange to Taiyuan people's ears. (Tan 1998: 50)

Versión española: Las recuerdo porque una de ellas producía unos sonidos acuosos, <<shrrhh, shrrhh $>>$. Cuando crecí pude reconocerlos como el acento de Pekín, que resulta siempre muy extraño a oídos de las gentes de Taiyuan. (Tan 2009: 60)

Wyah! Wyah! The sad lute music began again as the sky on the stage lightened (Tan 1998: 81).

Versión española: Wyah! Wyah! La triste música del laúd se reanudó, mientras se iluminaba el cielo sobre el escenario (Tan 2009: 105).

Me? Oh, I hated the American air force officers who said habbababba sounds to make my face turn red (Tan 1998: 22)

Versión española: En cuanto a mí, detestaba a los oficiales de las fuerzas aéreas norteamericanas, los que hablaban con aquellos sonidos incomprensibles que me hacían enrojecer (Tan 2009: 21).

En los dos primeros ejemplos, las onomatopeyas "shrrhh, shrrhh" y “Wyah! Wyab!” no son habituales en el inglés americano. "Shrrbh, shrrbh" debería ser la imitación de los sonidos retroflejos (juan she yin) y er hua yin, que se refiere al sufijo " $e r$ " que se añade a los sustantivos, sonidos especiales que sólo existen en el chino mandarín y en algunos dialectos del Norte de China. Como la protagonista Lindo era de Taiyuan, cuyo dialecto no tiene estos sonidos, le parece muy rara la pronunciación de Huang Taitai. "Wyah! Wyah!” es una onomatopeya inventada por la autora y se usa aquí para imitar el sonido del laúd, instrumento musical que acompaña el canto de la ópera china. En la versión española, el traductor mantiene intactas estas onomatopeyas, tomando en consideración que estos sonidos serían exclusivos de la cultura china. En eltercer ejemplo, la onomatopeya "habba-habba" tampoco es habitual en inglés. Es, en realidad, una invención de la autora. En la novela, la madre de Jing-mei Woo, Suyuan Woo, usa "babba-habba" para describir el modo de hablar de los oficiales americanos cuando hablan inglés, idioma que le parece muy extraño. En la versión castellana, el traductor opta por omitir esta onomatopeya explicitando directamente lo que intenta transmitir la autora. Por ejemplo, el traductor interpreta esa "habba-habba" como "sonidos incomprensibles". Quizá 
aquí el traductor creyera que, para un lector occidental, el sonido "babba-babba" sería demasiado raro para describir la pronunciación del inglés, idioma que resulta más familiar para ellos.

Al observar estos casos concretos, hemos notado que en la traducción española, en general, el traductor conserva las onomatopeyas originales u omite el sonido pero al mismo tiempo añade elementos descriptivos como compensación. Sin embargo, la retrotraducción de estos sonidos en las versiones chinas no resulta tan fácil, porque las traductoras chinas han de buscar una manera adecuada para que los lectores chinos puedan "reconocer" estos sonidos y establecer correspondientes asociaciones. Por ejemplo, en cuanto a la traducción de "shrrhh, shrrhh" del primer ejemplo, Yu opta por omitir la onomatopeya explicitando el sonido er hua; en la versión de Cheng, se reescribe la frase “wateryshrrhh, shrrhb” como “把小孩尿尿的发出的嘘嘘声” (pronunciado como un sonido $x u x u$, parecido al que produce una madre cuando sostiene a su bebé para ayudarle a orinar) (Cheng 2006: 41). En el caso de “Wyah! Wyah!', en la versión de Tian y Cheng, se omite la onomatopeya que les resulta extraña para describir el sonido del laúd; en la versión de Yu, se traduce como “嘈嘈切切凄凄” (caocao qieqie qiqi) (Yu 1990: 75), invención de la traductora, que imita el verso de Li Qingzhao, famosa poeta china de la dinastía Song, “凄凄惨惨戚戚” (qiqi cancan qiqi), que describe la tristeza y la soledad que sufre la poeta. A través de esta traducción, notamos que la influencia de la intertextualidad o "textual grid" (Bassnett y Lefevere 2001: 5) de la cultura de llegada es indudable. En torno a la traducción de la onomatopeya “habba-habba”, Tian la sustituye por “吼里呱啦” (jiliguala) (1992: 8) y Yu la traduce como “吼里咕噜” (jiligulu) (1990: 8): ambas son onomatopeyas del chino que sirven para describir el balbuceo que produce una persona cuando habla.

\subsection{LA TRADUCCIÓN DE LOS NOMBRES PROPIOS}

Los nombres propios, que sirven para hacer referencia a los individuos, a los lugares, a las instituciones sociales, etc., constituyen una parte imprescindible de una cultura. No es exagerado decir que los nombres propios representan la cultura de que forman parte de manera condensada, porque en ellos se proyectan la esencia cultural, la historia, las actitudes y creencias de la gente, la visión del mundo y el modo de vivir de un pueblo, etc. En los últimos años, a la hora de traducir los nombres propios, sobre todo, los topónimos y los nombres de personas, se inclina a aplicar la traducción fonética en la que no se explicitan sus connotaciones culturales con el fin de aumentar su expresividad. Sin embargo, según algunos teóricos de la traductología, como 
Tymoczko (1999: 225), esta manera lingüística de traducir los nombres propios provocará problemas en la cultura meta; de ahí que haya que darse cuenta de que los nombres propios no sólo sirve como etiqueta de un objeto, un lugar o una persona sino que también tienen sus propias funciones semánticas y semióticas que hacen recordarun referente único.

¿Cómo se traducen los nombres propios? Parece que los traductores entran en un callejón sin salida, porque: "if the name is transferred orthographically, the name is lost because a new name is created phonologically; and if the name is translated, the name is lost because a new name is created orthographically or semantically" (Tymoczko 1999: 239). Sería muy difícil llevar a cabo una traducción fonética y semática al mismo tiempo. A continuación, veremos cómo seleccionan estrategias traslativas los traductores de The Joy Luck Club a la hora de traducir los nombres propios.

\subsubsection{La traducción de los topónimos}

Sin duda alguna, los topónimos en muchas ocasiones no sólo constituyen un signo que hace referencia a un país, a un lugar o a una calle, sino que también acarrean una profunda connotación histórica y cultural. En cierto sentido, la evolución de los topónimos deja ver los acontecimientos o transformaciones que han tenido lugar en un país o en un lugar a lo largo de la historia. Además, en el contexto postcolonial, los topónimos también cobran un nuevo sentido político e ideológico. El rechazo de ciertos topónimos convencionales que Occidente denominaba determinados lugares del mundo periférico ha llegado a ser una de las medidas de resistencia contra la hegemonía cultural que toman los países periféricos, lo que es favorable para fomentar la consolidación de distintas culturas nacionales.

Tomemos la traducción de “北京”, la capital de China como ejemplo. En los últimos años, en lugar de utilizar Peking o Pekín, forma convencional que denominaban 北京 los países anglo-americanos o hispanohablantes, Beijing, traducción fonética según el pinyin del mandarín chino, va siendo conocido por más gente de todo el mundo como la forma estándar de la capital de China. Como hemos visto, los cambios morfológicos en la traducción de los topónimos chinos constituyen una reivindicación política. En cierto sentido, podemos decir que el uso cada día más frecuente de las traducciones "corregidas" de los topónimos chinos supone la elevación de la posición política de China en el mundo.

En el último capítulo de The Joy Luck Club, "A Pair of Tickets", la protagonista de la novela, Jing-mei, también habla de los cambios morfológicos 
de los topónimos chinos que ponen de manifiesto las transformaciones que han tenido lugar en China:

In less than three hours, we will be in Guangzhou, which my guidebook tells me is how one properly refers to Canton these days. It seems all the cities I have heard of, except Shanghai, have changed their spellings. I think they are saying China has changed in other ways as well. Chungking is Chongqing. And Kweilin is Guilin (Tan 1998: 268; énfasis mío).

Quizá, para un traductor español, al traducir este párrafo, no tenga ninguna dificultad. Lo que tiene que hacer es traducir literalmente el texto original al español. Sin embargo, a las traductoras de las versiones chinas cómo transmitir estos cambios morfológicos de los topónimos chinos producidos en el mundo occidental a los lectores chinos y cómo hacerles tener en cuenta la connotación que está detrás de estos cambios no les resultan fácil. Aquí merece la pena mencionar la versión de Tian. A diferencia de las otras traductoras, que omiten las diferentes formas de los topónimos diciendo simplemente "Parece que todas las ciudades de que he oído hablar, excepto Shanghai, han cambiado la forma en que se deletrea", Tian mantiene las "antiguas" formas occidentales en su texto traducido para que los lectores chinos puedan percibir los cambios morfológicos que se producen en la traducción de los topónimos. Además, la traductora también añade un modificador al verbo "change" de la frase "China has changed in other ways as well", traduciéndola como "... en China se han producido muchos cambios titánicos y estremecedores en diversos aspectos" para poner énfasis en el sentido político de estos cambios morfológicos de los topónimos chinos. Lo que sigue es su traducción:

\section{再过三个多小时, 我们就要到达广州了。旅游书上说广州 (Guangzhou) 就是以前的Canton, 我所知道的许多城市, 除 了上海之外，都改变了它们的英文拼法，这还说明中国在 许多方面发生了天翻地覆的变化。重庆 (Chungking) 是 Chongqing, 桂林 (Kweilin) 是Guilin,...... (1992: 291).}

Los textos postcoloniales, en cierto sentido, "en sí ya llevan la carga de la traducción, ya constituyen una traducción, han surgido como resultado de un proceso traductor en el ámbito de la creación" (Sales 2004: 466). Las obras de Amy Tan tampoco son una excepción. En este sentido, se puede decir que los topónimos chinos que usa la autora en el texto original en realidad son la versión americana de los topónimos chinos. Aunque biológicamente es china, en ciertas ocasiones la autora conoce China desde una perspectiva occidental, y esta versión americana de los topónimos chinos en cierto sentido puede ser una 
señal que marca la parte americana de su identidad híbrida. Creemos que en la versión de Tian, la traductora no sólo muestra los cambios morfológicos de los topónimos chinos producidos en Occidente sino también que revela a los lectores chinos la identidad híbrida de la protagonista de la novela, o, mejor dicho, de la misma autora.

\subsubsection{La traducción de los nombres de las personas}

En The Joy Luck Club, aparte de los topónimos, la autora también introduce muchos nombres chinos que llevan profundas connotaciones. Como es sabido, aparte de la lengua que habla una persona, su nombre también constituye una marca de su identidad cultural, porque cada cultura tiene su propia manera de construir los nombres. En la cultura china, cuando nace un bebé, sus padres o familiares siempre eligen caracteres con pronunciación melodiosa y que al mismo tiempo contienen significados positivos o prometedores con el fin de desear al recién nacido un futuro brillante o expresar el deseo familiar que aspiran colmar. En muchas ocasiones, los nombres chinos constituyen un significante en el que se combinan valores semánticos, semióticos y estéticos. Por la intensa carga cultural que llevan los nombres, al transmitirlos a otra cultura surgen muchos problemas. Al respecto, Tymoczko ha comentado con las siguientes palabras:

Not only do names in many cultures have lexical meaning, they function as sociolinguistic signs, indicating tribal and family affiliation; gender and class; racial, ethnic, national, and religious identity; and the like. They are dense signifiers, signs of essential structures of human societies. Thus, names are often among the semiotic elements of a text that are the most urgent to transpose and at the same time the most problematic to translate, in part because their semiotic significance is so often culturally specific and dependent on cultural paradigms (1999: 224).

Como hemos dicho anteriormente, la obra original en sí misma constituye una traducción. En este sentido, los nombres chinos que usa la autora en el texto original ya suponen una traducción según su entendimiento de la cultura china. Sin embargo, parece que la autora sólo pone énfasis en los significados semánticos de los nombres ignorando otros factores muy importantes que hay que tomar en consideración al elegir los caracteres chinos, por ejemplo, el sonido de los caracteres o el género de la persona, etc.

En la cultura china, aunque a la hora de dar nombre a una persona la gente prefiere elegir caracteres chinos que llevan sentidos especiales, no todos 
los caracteres son adecuados para formar un nombre. Además, el género también es un factor que hay que tomar en consideración. En general, si el nombre es para una chica, se inclina a elegir caracteres que están asociados a la ternura, el carácter minucioso y sentimental que se atribuye culturalmente a las mujeres, por ejemplo, las plantas, como “花” (bua, flor), 柳 (liu, sauce), los fenómenos naturales, “云” ( $y u$, nube), “雨” ( $y u$, lluvia), las piedras preciosas, “玉” ( $y u$, jade), los adjetivos, “美” (mei, hermoso), “洁” (jie, puro), etc. Si el nombre es para un chico, se prefieren los caracteres que están relacionados con la firmeza o la fuerza, y las palabras que destacan la masculinidad, por ejemplo, las plantas, “松” (song, pino), “杨” (yang, álamo), los fenómenos naturales, “风”, (feng, viento), “海” (hai, océano), “峰” (feng, cumbre), los adjetivos, “刚”(gang, firme), “强” (qiang, fuerte), etc.

Al traducir estos nombres chinos, para el traductor de la versión castellana parece que no le es necesario tomar en consideración los factores que acabamos de mencionar. Traslada directamente al texto traducido los nombres chinos y las explicaciones que ha dado la autora, concediéndole toda la confianza sin poner en duda su autoridad y autenticidad como autora étnica. Sin embargo, para las traductoras de las versiones chinas, al retrotraducir estos nombres, la tarea no resulta muy fácil, porque los factores que ignora la autora dificultan y complican la elección de los caracteres.A continuación, veremos algunos ejemplos interesantes.

En el cápitulo "The Red Candle", la autora denomina al marido de Anmei "Tyan-yu", cuyo significado es: "tyan for 'sky'... and yu, meaning "leftovers" (Tan 1998: 51). Como la construcción de este nombre corresponde a las costumbres y los criterios de formar un nombre masculino, en todas las versiones chinas se traduce como “天余” (tian $y u$ ). Sin embargo, en cuanto a otros nombres, parece que las traductoras no llegan a un acuerdo.

En el cápitulo "Waiting between the Trees", Ying-ying explica que su propio nombre significa "Clear Reflection" (Tan 1998: 243). En la versión de Tian y la de Cheng, las traductoras traducen este nombre como “映映” (ying ying, con la cuarta entonación) que no sólo corresponde a Ying-ying fonéticamente sino que también coincide con el significado que explica la protagonista. Aunque en muchas ocasiones los nombres se construyen por la duplicación del mismo carácter, la repetición de ying con la cuarta entonación no es una forma usual. En la versión de $\mathrm{Yu}$, se traduce este nombre como “莹影” (ying ying, el primer carácter lleva la segunda entonación y el segundo, la tercera; “莹” es adjetivo y significa “claro” o “cristalino”; “影” es sustantivo y significa "sombra" o "reflejo”), que suena más evocador y se acerca más a los criterios estéticos chinos.

La traducción de Suyuan también puede ser otro ejemplo ilustrativo. Suyuan, el personaje más importante de la novela, que es la organizadora de 
"the Joy Luck Club" y el único miembro del club que falta en la mesa de mab jong, porque murió de un aneurisma cerebral. Aunque desde el comienzo de la novela Suyuan está ausente y sus historias han sido relatadas por su hija Jingmei, es el personaje que mantiene el hilo conductor de todo el libro. Al dar nombre a este personaje "central", la autora elige las palabras con todo esmero. Como explica la autora en la obra, "Suyuan" no es un nombre ordinario. Este nombre no sólo contiene una connotación profunda sino que también revela la intención creativa de la novela. Con la ausencia de Suyuan la autora intenta crear una sensación de desequilibrio; a lo largo de la novela, las hijas se esfuerzan para romperlo e intentan alcanzar una situación armónica. Al final de la novela, Jing-mei, sustituta de Suyuan, viaja a China y se reúne con sus hermanas que Suyuan dejó en dicho país. Con esta última escena, la novela termina felizmente con el cumplimiento del deseo que Suyuan albergó durante toda su vida. En la obra original, el padre de Jing-mei explica el significado del nombre Suyuan en su "inglés roto" de la siguiente manera:

\begin{abstract}
"'Suyuan'," he says..."The way she write it in Chinese, it mean 'Long-Cherished Wish.'...See this first character, it mean something like 'Forever Never Forgotten.' But there is another way to write 'Suyuan.' Sound exactly the same, but the meaning is opposite." His finger creates the brushstrokes of another character. 'The first part look the same: 'Never Forgotten.' But the last part add to first part make the whole word mean 'LongHeld Grudge.'...” (Tan 1998: 280).

Versión española: -Suyuan... Tal como ella lo usaba significa «Deseo largamente acariciado». ... Mira este primer ideograma, que significa algo así como «Eternamente nunca olvidada». Pero hay otra manera de escribir «Suyuan», que suena exactamente igual, pero su significado es el contrario. -Su dedo traza otro ideograma-. La primera parte es igual, «nunca olvidada», pero la otra parte que completa la palabra significa «rencor largamente mantenido»... (Tan 2009: 377).
\end{abstract}

Según las explicaciones del padre de Jing-mei, la traducción china de Suyuan puede ser “宿愿” o “夙愿”. Tian y Yu optan por traducireste nombre como “宿愿”; sin embargo, Cheng lo traduce como “素云” (su yun). Quizá la traductora tome en consideración que a pesar de que “宿愿” sea la palabra exacta que quiere insertar la autora en el texto original, no es una palabra adecuada para ser un nombre. Para reducir la sensación de extrañeza que tendría un lector chino, la traductora reconstruye este nombre según criterios chinos eligiendo dos caracteres que se usan con frecuencia en los nombres femeninos y se pronuncian fonéticamente parecidos a Suyuan pero con significados distintos (“素” significa “simple o de color claro” y “云” es nube). 
Al mismo tiempo, elimina la parte que contiene la explicación sobre el nombre en el texto traducido.

Otro ejemplo interesante sería la traducción del nombre Jing-mei. En el texto original, el padre de Jing-mei explica los significados implícitos de su nombre con las siguientes palabras:

“'Jing' like excellent jing. Not just good, it's something pure, essential, the best quality. Jing is good leftover stuff when you take impurities out of something like gold, or rice, or salt. So what is left -just pure essence. And 'Mei,' this is common mei, as in meimei, "younger sister." (Tan 1998: 280-1).

Versión española: Ese jing tiene un sentido de excelente, no sólo bueno, sino algo puro, esencial, de la mejor calidad. Jing es lo bueno que queda cuando quitas las impurezas de algo como el oro, el arroz o la sal, de modo que lo restante... es la esencia pura. En cuanto a Mei es el mei común, como en meimei, «hermana menor» (Tan 2009: 378).

Según la pronunciación y la explicación del carácter jing, en chino encontramos tres caracteres candidatos: “精”, “声” y “晶”. Aunque los significados de los tres caracteres se diferencian sutilmente (“精” pone énfasis en lo fino y lo refinado, “声”, lo esencial y “晶” se refiere a algo cristalizado y puro), el significado principal se centra en "lo bueno y lo esencial". En las versiones chinas, aparecen las tres opciones. En cuanto al segundo carácter mei, la explicación es muy clara: en chino el carácter “妹” sólo significa "hermana”. En la versión de Tian, se traduce este nombre como “晶妹” y en la traducción de Yu, “声妹”. Sin embargo, en la versión de Cheng, la traductora vuelve a apropiarse de este nombre traduciéndolo como “精美” (el segundo carácter se pronuncia mei y significa bueno) y reescribiendo las explicaciones en el texto traducido.

\subsection{LA RETROTRADUCCIÓN DE LOS TÉRMINOS CHINOS INVENTADOS POR LA AUTORA}

Para Amy Tan, aunque el chino no es totalmente desconocido, según ella misma reconoce, es "illiterate in Chinese" (Tan 2003: 261). Al escribir, un diccionario Pinyin-English constituye el principal instrumento con el que asocia el pinyin con sus correspondientes significados. Sin embargo, sabemos que los significados de los ideogramas chinos son muy complicados y flexibles, y siempre cambian según el contexto. Además, muchos caracteres chinos tienen diferentes pronunciaciones, en virtud de las cuales adoptan diferentes 
significados. Dado que la autora no maneja bien el chino, en ciertas ocasiones comete "errores" desde el punto de vista de la cultura tradicional china. Sin embargo, tenemos que darnos cuenta de que estos "errores", en cierto sentido, pueden ser nuevas "invenciones" que realiza la autora o constituyen una interpretación suya de la cultura china desde una perspectiva especial. Estos "errores" o "invenciones" constituyen una marca notable de su condición inbetween. En los siguientes dos ejemplos, veremos cómo tratan estas "invenciones" los distintos traductores a la hora de producir su versión.

My auntie, who had a very bad temper with children, told him he had no shou, no respect for ancestors or family, just like our mother (Tan 1998: 44).

Versión de Tian:

我的舅妈向来对小孩子没耐心, 她说弟弟不 shou

(孝), 对于长辈和家人不尊敬, 就象我妈妈一样。(1992:

34)

Versión de Yu:

我舅母对小孩脾气甚大, 告诉弟弟他不知《羞》, 就像我 们的妈妈一样, 不尊宗敬祖。(1990: 32)

Versión de Cheng:

舅母对待孩子, 向来粗暴的很。我弟弟不服地瞪了她一眼

，她马上训斥他目无尊长，

如此大逆不道的行为, 就像我们妈妈。(2006: 33)

Versión española: Mi tía, que tenía muy mal genio con los niños, le dijo que carecía de shou, es decir, de respeto hacia los antepasados de la familia, como le ocurría a mi madre (Tan 2009: 51).

En este ejemplo, "shou", según la explicación añadida por la autora, es el "respect for ancestors or family". Sin embargo, en el chino mandarín no existe ningún carácter que tenga este significado y se pronuncie de esta manera. Cabe pensar que el carácter que la autora quería usar sería “孝”, que se pronuncia "xiao". Al retrotraducir este término al chino, las tres traductoras han elegido diferentes estrategias: Tian mantiene ese "shou" que usa la autora en el texto original, pero a él añade el carácter correcto “孝”, marcándolo entre corchetes, para que el lector chino pueda mantener un contacto directo con el texto fuente y percibir su originalidad; Yu elige el carácter “羞” ( iu , que tiene una pronunciación parecida a “shou”. Sin embargo, “羞” significa "vergüenza”, que no coincide con la explicación que da la autora en el texto original; Cheng elimina directamente el término shou y hace una traducción libre que literalmente significa: "Con los niños, mi tía siempre era muy brutal. Mi hermano le dirigió una mirada irritada y de repente ella le reprochó que no tuviera respecto a los mayores, igual de mal que se comportaba mi madre". 
But he could not stop my mother from giving me her chang, a necklace made out of a tablet of red jade (Tan 1998: 53).

Versión de Tian:

但他并未阻止母亲再送给我个贴身的陪嫁, 一条用红玉穿

成的项链 (1992: 46)

Versión de Yu:

可是他挡不住我妈给我她的《璋》, 一块红玉砝的链子

(1990: 44).

Versión de Cheng:

但他还是阻止不了母亲给我的“私房”

一条玛瑙嵌镶的项链 (2006: 45).

Versión española: ...pero no pudo evitar que mi madre me diera su chang, un collar de jade rojo (Tan 2009: 65).

En este ejemplo, en lugar del término chang, quizá la autora quisiera decir cang, que en chino es “藏”, algo muy bien conservado por su gran valor. Tian al final elimina directamente este término en el texto traducido; Yu usa el carácter “璋” (zhang), que se pronuncia parecido a chang y significa "jade” en chino. Obviamente, Yu intenta buscar una palabra homófona de chang que tiene el significado correspondiente a "red jade", explicación que da la autora; Cheng traduce chang como “私房” (si fang), palabra compuesta por dos caracteres, que se refiere a algo valioso que una persona ha conservado en privado.

\subsection{LA TRADUCCIÓN DE LA REESCRITURA DE ELEMENTOS TRADICIONALES MITOLÓGICOS E INTERTEXTUALES}

La invención de algunas costumbres y alusiones literarias y la reescritura de ciertos elementos mitológicos tradicionales chinos en The Joy Luck Club también es un factor llamativo: por una parte, constituyen un bello realce que atrae la atención de los lectores que se interesan por la cultura china $y$, por otra, en cierto sentido, revisten la obra de un fuerte color orientalista y exótico que explica que se hayan convertido en el blanco de las agudas críticas de autores o estudiosos que intentan reivindicar la pureza o la autenticidad de la cultura china. A continuación, estudiaremos algunos ejemplos de esta categoría con el fin de analizar cómo las gestionan los traductores que se sitúan en diferentes contextos socio-culturales.

In America I will have a daughter just like me. But over there nobody will say her worth is measured by the loudness of her husband's belch (Tan 1998: 17). 
Versión española: En América tendré una hija igual que yo, pero allí nadie dirá que su valía se mide por la sonoridad del eructo de su marido (Tan 2009:15).

Versión de Cheng:

待到了美国, 我要生个女儿, 她会长得很像我。但是, 她 不用看着丈夫的眼色低眉垂眼地过日子。(Tan 2006:15)

Aunque en las épocas antiguas de China, la capacidad y habilidad de preparar bien la comida era uno de los criterios básicos para evaluar a una mujer, el "eructo" que hace un marido nunca llegó a ser un síntoma de aprobación. Es más, eructar en público es una manifestación de mala educación. Quizá en el texto original la autora adopta el sentido figurado de "eructo" con el fin de decir que una mujer tiene que cuidar bien a su marido en la comida. Sin embargo, un lector que no conoce la cultura china lo tomaría como una "verdadera" costumbre china. Hemos visto que en la versión española de este ejemplo esta costumbre "inventada" se transmite literalmente a los lectores españoles. Sin embargo, las traductoras de las versiones chinas eligen diferentes estrategias. Parece que Tian y Yu insisten en traducir fielmente el texto original, a pesar de que una traducción "fiel" produzca una sensación de extrañeza a los lectores chinos. En cambio, Cheng neutraliza esta costumbre "rara" y la reescribe como "En América tendré una hija igual que yo, pero allí no va a pasar los días humilde y sumisa sopesando el gesto de su marido".

On Joy Luck nights, my parents brought me to the Hsus'. Since I was the guest, I had to take care of all the younger children... (Tan 1998: 28).

Versión española: Las noches en que había reunión del club, mis padres me llevaban a casa de los Hsu. Como era la invitada, tenía que cuidar de los niños más pequeños (Tan 2009: 30).

Versión de Tian:

\section{一到喜福会聚会的夜晚, 父母就带我去苏家。尽管我是客}

人，但也不得不照看那些比我小的孩子。(1992: 15)

Versión de Cheng:

在那些父母去许家聚会的晚上，他们也会带上我。因为我 是那里的孩子们中最年长的, 我就必须得要看管住其他几 个小孩子...... (2006: 15)

En este ejemplo, según lo que dice la autora, parece que los chinos tienen la costumbre de que los invitados cuiden a los niños de la familia anfitriona. Quizá esta costumbre no sólo resulte un poco extraña a los lectores españoles sino también a los lectores chinos. Vemos que en la versión española se mantiene "intacta" esta costumbre. Sin embargo, las traductoras de las versiones chinas eligen diferentes estrategias. Al contrario que $\mathrm{Yu}$, quien 
traduce esta costumbre literalmente, Tian y Cheng, hacen ciertos ajustes. Creyendo más lógico que el o la mayor de los niños cuide de otros menores en el caso de que los invitados sean amigos íntimos de la familia anfitriona, traducen la frase "Since I was the guest, I had to take care of all the younger children..." respectivamente como "A pesar de ser la invitada, tenía que cuidar de los otros niños menores que yo" y "Como yo era la mayor de los niños, tenía que cuidar de los otros". Hemos notado que muchos "malentendidos culturales" suscitados por los autores por falta de suficiente conocimiento sobre su cultura étnica o por sus invenciones creativas terminan siendo transmitidos a los lectores occidentales a través de las traducciones. A causa de la falta de distinción entre lo que se presenta como supuestas tradiciones en las creaciones literarias y las tradiciones culturales, este conjunto de conocimientos "refractados" de la cultura china conducirá a la construcción de una representación "deformada" y reforzará los estereotipos de la cultura china en Occidente.

Aparte de inventar ciertas costumbres chinas, en The Joy Luck Club, la autora también "crea" ciertos poemas antiguos chinos e "imita"ciertos refranes confucianos, lo que añade a la obra un color exótico.

...Autumn moon warms. O! Geese shadows return," Baba was reciting a long poem he had deciphered from ancient stone inscriptions.

...

“Mist flowers radiant” (Tan 1998: 70-1).

Versión de Tian: 秋月暖兮, 我影扫 (Qiuyue nuan xi, eying gui)

雾花飞兮... (wubua fei xi...) (1992: 65)

Versión de Yu: 秋月暖兮, 我鸟影归 (Qiu yue nuan xi, eying gui)

雾花灿兮... (wubua can xi...) (1990: 59)

Versión de Cheng: 秋月怡人，荷塘鹤影... (2006: 62)

(Qiuyue yiren, hetang heying)

Versión española: -...La luna de otoño se calienta. ¡Oh! Las sombras de los gansos retornan. -Baba recitaba un largo poema que había descifrado de antiguas inscripciones en piedra-.

-Radiantes flores de la bruma. ¡Oh!... (Tan 2009:90).

En estos versos, aparecen la luna, los gansos, las flores y la niebla, figuras que, desde un punto de vista occidental, parecen muy orientales o destilan un fuerte sabor chino. También notamos que en el texto original, la autora omite los artículos definidos que debían aparecer antes de las locuciones "Autumn moon", "Geese shadows" y "Mist flowers", para que el poema evoque más el elemento chino. Vemos que el traductor de la versión española 
transmite estas imágenes y mantienen la estructura del poema en el texto traducido; el único ajuste que hacen es añadir los artículos omitidos intencionadamente por la autora en el texto original.

$\mathrm{Al}$ retrotraducir este poema al chino, la situación es demasiado complicada: dado que es un poema realmente existente, las traductoras tienen que localizar el texto original e insertarlo en el texto traducido; si es una invención creativa de la autora, han de "reconstruirlo" según las reglas estilísticas y estéticas de los poemas chinos antiguos. Estilísticamente, tomando en consideración el uso de las interjecciones en los versos, Tian y Yu traducen estos versos según el estilo de los poemas de Shijing ${ }^{1}$ y Chuci $^{2}$, sustituyendo la interjección “O” por “兮” ( $x$, partícula modal que sirve para ajustar la rima y expresar sentimientos).

Cheng traduce el primer verso de manera libre (su versión en español significa: "la luna de otoño es agradable, las sombras de las grullas se reflejan en el estanque de lotos") y omite el segundo verso. Obviamente, la traductora ha añadido "el estanque de lotos" en el texto traducido y ha sustituido el ganso por la grulla, pájaro que simboliza una larga vida en la cultura china. Hay que destacar que esta reescritura no es una invención caprichosa que se le ocurre de manera irracional. A un lector chino de nivel medio, al leer este verso en el que aparecen la luna, la sombra de los gansos y el otoño, le viene a la mente inmediatamente otro verso muy famoso proveniente de El sueño en el pabellón rojo, “寒塘渡鹤影, 冷月葬花魂” (“En el estanque frío de lotos/ se reflejan las sombras de las grullas/ y la luna helada/ está rindiendo homenaje/ a las flores abochornadas" [mi traducción]). A causa de esta intertextualidad, la traductora intenta crear un poema con más valor poético y estético.

Aparte de aquellos versos antiguos, la autora también inserta una "noticia" en el capítulo "Magpies". Según la autora o la narradora, ha leído en una revista de China. El texto original reza como sigue:

.... read this news in a magazine from China.

It said that for thousands of years birds had been tormenting the peasants. They flocked to watch peasants bent over in the fields, digging the hard dirt, crying into the furrows to water the seeds. And when the people stood up, the birds would fly down and drink the tears and eat the seeds. So children starved.

${ }^{1}$ Es la primera antología de poemas de China, en la que se incluyen más de trescientos poemas populares creados durante unos seiscientos años (desde principios de la dinastía Zhou del Oeste [siglo XI a.c - 771 a.c.] hasta mediados del Periodo de Primavera y Otoño [770 a.c - 476 a.c.]). ${ }^{2}$ Chuci es un estilo de poemas que surge en torno a finales del periodo de los Reinos Combatientes (siglo $\mathrm{V}$ a.c.-221 a.c.) y estuvo de moda en las tierras del reino Chu. Sus principales representantes son $\mathrm{Qu}$ Yuan y Song Yu. 
But one day, all these tired peasants -from all over China- they gathered in fields everywhere. They watched the birds eating and drinking. And they said, "Enough of this suffering and silence!" They began to clap their hands, and bang sticks on pots and pans



And all these birds rose in the air, alarmed and confused by this new anger, beating their black wings, flying just above, waiting for the noise to stop. But the people's shouts only grew stronger, angrier. The birds became more exhausted, unable to land, unable to eat. And this continued for many hours, for many days, until all those birds -hundreds, thousands, and then millions! -fluttered to the ground, dead and still, until not one bird remained in the sky. (Tan 1998: 241).

La veracidad de esta noticia ya no se puede confirmar y es muy posible que la autora invente esta "alusión" haciéndose eco de la historia sobre las urracas que se relata en el comienzo de este capítulo. En la cultura china, la urraca está considerada un tipo de pájaro que puede traer buena suerte a la gente. Por lo tanto, en China, la gente llama este pájaro “喜鹊” (xique, el pájaro de felicidad). Sin embargo, en el comienzo de este capítulo, la autora nos da otra versión de este pájaro. Según ella, las urracas son las aves que comen las lágrimas de las chicas infelices. En su versión, la urraca se convierte en un pájaro ingrato cuya felicidad se nutre de los dolores de los demás. Con esta historia, la narradora posiblemente quiera decir que, si bien en las épocas antiguas de China las mujeres no podían controlar su propio destino y lo único que podían hacer era tragar sus propias lágrimas para no sufrir los ataques de las urracas, en la América moderna sus hijas pueden elegir lo que quieren hacer y dominar sus propios destinos. La noticia que aparece en el final de ese capítulo intenta transmitir esta idea.

Sin duda, esta nueva versión de la urraca y la noticia china hacen que este capítulo esté revestido de un fuerte tono misterioso. Notamos que en laversión españolael traductor no hace ningún cambio, ni tampoco reescribe ninguno de los detalles. Sin embargo, las traductoras del chino toman diferentes opciones: Tian y Yu traducen esta noticia con el fin de mantener la integridad de todo el capítulo;en cambio, Cheng, poniendo en duda la veracidad de esta noticia, la omite en su versión y hace una reescritura:

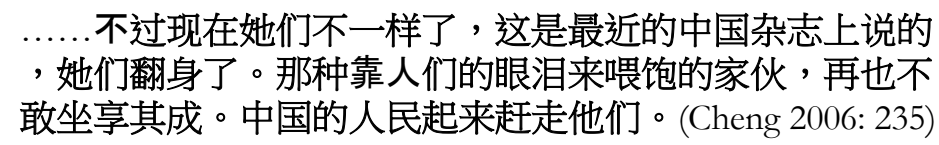


[... Sin embargo, ahora ellas no son iguales (que las mujeres que vivían en el pasado), eso es lo que dicen recientemente las revistas de China, las mujeres se han emancipado. Los pájaros que viven de las lágrimas ajenas ya no se atreven a disfrutar del beneficio de lo que han hecho los otros. El pueblo chino se ha levantado a expulsarlos.]

Para que la obra original tenga más sabor chino, la autora también crea unos refranes confucianos. $\mathrm{Al}$ respecto, veremos un ejemplo.

So he came back and made a Confucius joke, that if the words were wrong, then his intentions must also be wrong (Tan 1998: 264).

Versión de Tian:

他明白过来, 开了个很有哲理的玩笑说：词不达意呀。(19 92: 287)

Versión de Yu:

所以他回头编造了一个子曰的笑话, 说是如果语彙有误, 那么他的心术必然不正。(1990: 291)

Versión de Cheng: Cero traducción.

Versión española: Él replicó con una broma confuciana, diciéndome que si las palabras eran erróneas, entonces las intenciones también debían serlo (Tan 2009: 355).

En este ejemplo, la frase marcada por "Confucius joke" en realidad es algo que "inventa" la propia autora. En la versión española, el traductor transmite esta información directamente en el texto traducido; de esta manera, los lectores españoles tomarán esta creación literaria de la autora como propio del estilo humorístico confuciano. Sin embargo, las traductoras de las versiones chinas emplean diferentes estrategias. Tian hace ciertos ajustes: traduce "made a Confucius joke" como "hizo una broma de manera filosófica" para neutralizar la sensación de extrañeza y reescribe la última frase como "las palabras no logran expresar bien lo que piensa una persona"; aunque Yu traduce toda la frase (manteniendo "a Confucius joke"), sustituye el verbo "make" por el "inventar" para declarar que esta broma es una versión propia del hablante; Cheng opta por eliminar toda esta frase en el texto traducido.

Las leyendas y los mitos tradicionales de la cultura china constituyen una fuente inagotable de inspiración en la creación literaria de Amy Tan. Igual que Kingston, en The Joy Luck Club, la autora no sólo reescribe ciertos mitos tradicionales chinos sino que también concede nueva vida a ciertos personajesmitológicos o "inventa" ciertos personajes históricos. En la novela, podemos ver una reescritura de la leyenda de Chang'e, la reelaboración de la historia de la venganza del Rey Dragón, etc. 
En la cultura china Chang'e es conocida como la diosa de la luna. En esta novela, la autora reescribe la leyenda de Chang'e mezclándola con la historia romántica de amor protagonizada por Niu Lang y Zhi Nv. Zhi Nv, la séptima hija de la Reina de los Cielos del Oeste, se enamoró de Niu Lang, un chico común y corriente, que vivía en un pueblo pobre de la Tierra. A pesar de la oposición del Cielo, Zhi Nv decidió casarse con Niu Lang y tuvo dos hijos con él. Para separarlos, la Reina de los Cielos del Oeste dibujó un río en el cielo, que es la Vía Láctea, para que los dos no se vieran nunca jamás. Conmovidas por el gran amor entre los dos, cada año el día siete del séptimo mes lunar, las urracas forman un puente sobre este río celestial con sus propios cuerpos, por el cual Niu Lang y sus hijos pueden subir al cielo y cruzar el río con el fin de reunirse con Zhi Nv. Para conmemorar esta leyenda, hoy en día en China se celebra en esa fecha la fiesta de los enamorados.

En China la leyenda de Chang'e también tiene muchas versiones populares. La que se ha erigido en clásica es la siguiente: en los tiempos lejanos, en el cielo había diez soles que iban secando la tierra y matando las plantas con su ardor. Para salvar al pueblo, Hou Yi, el marido de Chang'e, quien era arquero y tenía un arco mágico, mató a los nueves soles que estaban amenazando la vida del pueblo. En señal de agradecimiento, la Reina de los Cielos del Oeste le regaló una medicina mágica que le ayudó a mantener la juventud y a evitar la muerte. Por curiosidad, Chang'e probó esta medicina a escondidas y, al tomarla, empezó a ascender hacia la luna. Desde aquel entonces, se quedó en la luna y nunca volvió a ver su marido. En la luna sólo la acompañaban el frío y la soledad, castigos que tenía que recibir por su acción.

En la versión reescrita por la autora, Hou Yi se convierte en el "Master Archer of the Skies" (Tan 1998: 80) que vive en el sol. Día tras día y noche tras noche, Hou Yi y su mujer pasan uno tras otro sin verse, menos el día 15 del octavo mes lunar, que es la Fiesta de la Luna, como canta Chang'e en la novela:

\begin{abstract}
"My fate and my penance," she began to lament, pulling her long fingers through her hair, "to live here on the moon, while my husband lives on the sun. So that each day and each night we pass each other, never seeing one another, except this one evening, the night of the mid-autumn moon" (Tan 1998:80).
\end{abstract}

Además, la autora también explica el comportamiento egoísta de Chang'e con los conceptos filosóficos chinos, "yin" y "yang": "For woman is yin,... the darkness within, where untempered passions lie. And man is yang, bright truth lighting our minds" (Tan 1998: 81). Según la autora, el "yin", que simboliza la feminidad, es la parte oscura de los seres humanos, de la que se generan "las pasiones incontroladas" y, al contrario, el "yang", que representa la masculinidad, es la parte clara de la humanidad que otorga la ilustración 
racional a los seres humanos. Huelga decir que esta nueva interpretación de los conceptos "yin" y "yang" da a la obra un tono misterioso.

Vemos que en la versión española se mantiene esta reescritura de la leyenda de Chang'e. Sin embargo, las traductoras de las versiones chinas no han llegado a un acuerdo en torno a la traducción de esta reescritura. Tian y Yu vierten fielmente lo que recrea la autora. Al contrario, Cheng opta por omitir la parte trasplantada de la leyenda de Niu Lang y Zhi Nv, lo que en cierto sentido acerca el texto traducido a los lectores chinos. En otras palabras, la traductora opta por preservar la pureza de la cultura china desde una perspectiva ortodoxa china.

En el capítulo "Half and Half", la autora cuenta un suceso curioso que ocurrió a un niño, que recuperó misteriosamente el brazo que perdió en un accidente causado por unos fuegos artificiales en un rito mágico que hizo su madre. En esta historia, Tan "recrea" la figura del dios de fuego, Chu Jung, que según la autora, es "the three-eyed god of fire" (Tan 1998: 128). Aquí, esta figura mitológica es una mezcla del personaje legendario chino Zhu Rong, que mantiene el fuego y enseña al pueblo a utilizarlo, y la figura del dios del fuego del Taoísmo, Ma Wang Ye, quien tiene tres ojos. Aparte de esta historia, la autora también apunta a un rito que hace la madre de Rose para rendir homenaje al Rey Dragón con el fin de que le devuelva a su hijo Bing, inventando a su manera el procedimiento del rito y las razones por las que el Rey Dragón ha encarcelado a Bing. El texto original es el siguiente:

"I remember a boy who lost his hand in a firecracker accident," she said. "I saw the shreds of this boy's arm, his tears, and then I heard his mother's claim that he would grow back another hand, better than the last. This mother said she would pay back an ancestral debt ten times over. She would use a water treatment to soothe the wrath of Chu Jung, the three-eyed god of fire. And true enough, the next week this boy was riding a bicycle, both hands steering a straight course past my astonished eyes!"

"An ancestor of ours once stole water from a sacred well. Now the water is trying to steal back. We must sweeten the temper of the Coiling Dragon who lives in the sea. And then we must make him loosen his coils from Bing by giving him another treasure he can hide."

My mother poured out tea sweetened with sugar into the teacup, and threw this into the sea. And then she opened her fist. In her palm was a ring of watery blue sapphire, a gift from her mother, who had died many years before. This ring, she told me, drew coveting stares from women and made them inattentive to the 
children they guarded so jealously. This would make the Coiling Dragon forgetful of Bing. She threw the ring into the water (Tan 1998: 128-9).

Sin lugar a dudas, estos párrafos han concedido al texto original un fuerte tono misterioso. En la traducción española, esta historia misteriosa logra conectar con los lectores españoles y quizá llegue a ser uno de los puntos que atraen la atención de los lectores. En las versiones chinas de Yu y Tian, ambas traductoras mantienen estos párrafos, pero en la versión de Cheng (2006: 119), sólo se traduce el rito que hizo la madre de Rose (el último párrafo de la cita) y se reducen los otros párrafos a una frase: “从前在中国时，人们都用这种方法来祭海，以平息龙王的怒气。而这 通常是很有效的” (En las épocas antiguas de China, para extinguir la furia del Rey Dragón, la gente rendía homenaje al mar de esta manera, la cual era muy eficaz), con la que se une el texto que precede con lo que sigue.

A través de estos ejemplos, hemos visto que no podemos ignorar la función metonímica que cumplen las mitologías en una cultura. Como indica Tymoczko: "[f]or a traditional audience each telling evokes metonymically all previous telling of the tale that audience has participated in and, further, the telling instantiates and reifies metonymically the entire tradition that the audience and teller share" (1999: 43). Así, sin duda, las reescrituras de las mitologías tradicionales chinas que no encajan en los conocimientos acumulados de un lector tradicional le permitirán "correct (and forgive) the mistakes or omissions of traditional tellers" o "fill gaps in narrative textures" (Tymoczko 1995: 16). De ahí que veamos que las traductoras de las versiones chinas hacen ciertos ajustes tomando en consideración el bagaje cultural de los lectores chinos tradicionales.

\section{REFLEXIONES SOBRE LA RETROTRADUCCIÓN DE LA LITERATURA CHINOAMERICANA}

A través de analizar los ejemplos que hemos citado, notamos que la versión china de Cheng tiene muchas "discrepancias" con la obra original. Aunque decimos que la traducción es una actividad creativa, también sabemos que el traductor o la traductora no goza de la misma libertad que el autor o la autora de la obra original. A pesar de que la traducción no pueda ser igual que la obra original, "tampoco puede ser un texto diferente, porque si lo fuera sería tan o más peligroso que la tradicional aceptación de la neutralidad y de la equivalencia" (Vidal 2010: 101). Además, vemos que la reescritura de las tradiciones y las mitologías tradicionales en los textos postcoloniales siempre 
implica la lucha contra una doble atadura o una doble marginalización por parte de la cultura tradicional ortodoxa y la cultura dominante, como Mehrez ha mostrado:

These texts seek to decolonize themselves from two oppressors at once, the western ex-colonizer who naively boasts of their existence and ultimately recuperates them and the 'traditional', national cultures which shortsightedly deny their importance and consequently marginalize them (1992: 121).

En este sentido, una traducción en la que se silencia la propia voz de los autores híbridos no parece ser una manera adecuada a través de la cual conocer verdaderamente sus singularidades.

Aunque en el apartado anterior hemos especificado cuál es la versión clásica de estas leyendas y las mitologías chinas, nuestro interés no se centra en criticar la falsedad de las invenciones literarias de los autores chinoamericanos ni tampoco en salvaguardar la autenticidad y la autoridad de la cultura tradicional china desde una perspectiva cultural ortodoxa. Lo que intentamos hacer es indicar la diferencia que existe entre la cultura china y la chinoamericana, y plantear ciertas reflexiones sobre los dilemas a los que se enfrenta la traducción de las obras postcoloniales: ¿tienen el derecho a "corregir" lo que consideran "falso" los traductores para que el texto traducido no resulte tan "ridículo" a los lectores tradicionales? Desde el punto de vista del traductor o traductora occidental que no tiene mucho conocimiento de las culturas étnicas implicadas en estas obras, ¿qué tiene que hacer para revelar a sus lectores meta las singularidades de una cultura in-between? Un traductor o una traductora multicultural que está situado/a en el punto de encuentro entre las culturas matrices donde nace la hibridación cultural y otra ajena a la que se traducirá la obra, ¿qué tiene que hacer para poder introducir en esta cultura meta de manera adecuada la cultura tradicional y la híbrida?

Hay que entender estas invenciones o reescrituras desde una perspectiva "in-between". Es decir, por una parte, no podemos criticar o intentar "corregir" lo inventado o lo "falso"de estas reescrituras, porque "[i]t permits the adaptation of traditional content and form to new circumstances, allowing change while still maintaining a predominant sense of the preservation of larger elements of tradition" (Tymoczko 1999: 46) y constituye una manera eficaz de mantener la continuidad de las tradiciones culturales en un grupo diaspórico; por otra, tampoco podemos tratar estas reescrituras ciegamente haciendo caso omiso a los "efectos negativos" que producirán en la construcción de la imagen de la cultura china en otras culturas, por ejemplo, el refuerzo de los estereotipos orientalistas de los chinos y de la cultura china. De hecho, tomando en consideración las funciones metonímicas de la literatura étnica, es 
muy posible que estas reescrituras o invenciones creativas individuales se vayan ampliando hasta convertirse en elementos capaces de representar lo colectivo. En otras palabras, la obra de Amy Tan no sólo construye una imagen de los chinoamericanos en el mundo occidental sino también de los chinos en sentido amplio. Por lo tanto, los traductores postcoloniales han de mantener una actitud prudente, tomando en consideración todas las fuerzas culturales que están implicadas en el proceso traslativo, como indica África Vidal:

Traducir es reescribir, pero no como una vuelta a lo primigenio sino más bien como un desenmascaramiento de las múltiples voces que en realidad se superponen. [...] La reescritura supone repensar los distintos modelos de pensar, reflexionar sobre el orden generado por los mismos, desconstruir en cierta medida la retórica de los conjuntos previamente organizados de significantes. El traductor, en suma, al reescribir a quien está fuera de lugar, deberá entablar un debate constante con los sentidos heredados, que van configurándose a través de habitus y capitales simbólicos diferentes, con el fin de recuperar lo más completamente posible el discurso tomando en consideración la relación entre los diferentes valores que hay en juego en un intercambio comunicativo, pero a sabiendas también de que su labor no se salva de la manipulación (Vidal 2010: 100).

\section{BIBLIOGRAFÍA}

Bassnett, Susan y André Lefevere (2001). Constructing Cultures. Essays on Literary Translation. Shanghai, Shanghai Foreign Language Education Press.

Mehrez, Samia (1992). "Translation and the post-colonial experience: the francophone North Africa text" en L. Venuti (ed.): Rethinking Translation: Discourse Subjectivity Ideology. Londres, Routledge, pp. 120-138.

Sales, Dora (2004). Puentes sobre el mundo. Cultura, traducción y forma literaria en las narrativas de transculturación de José María Arguedas y Vikram Chandra. Berna, Peter Lang.

Tan, Amy (1990). Xifubui. Renrui Yu (trad.). Taibei, Unitas.

Tan Amy (1992). Xifubui. Qing Tian (trad.). Shenyang, Chunfeng Wenyi Press.

Tan, Amy (1998). The Joy Luck Club. Londres, Vintage.

Tan, Amy (2003). The Opposite of Fate: Memories of a Writing Life. Nueva York, Penguin.

Tan, Amy (2006). Xifubui. Naishan Cheng (trad.). Shanghai, Shanghai Translation Publishing House. 
Tan Amy (2009). El club de Buena estrella. Jordi Fibla (trad.). Barcelona, Planeta, S.A.

Tymoczko, Maria (1995). "The Metonymics of Translating Marginalized Texts" en Comparative Literature, No. 47, vol.1, pp. 11-24.

Tymoczko, Maria (1999). Translation in a Postcolonial Context. Manchester, St. Jerome.

Venuti, Lawrence (ed.) (1992). Rethinking Translation: Discourse Subjectivity Ideology. Londres, Routledge.

Vidal, África (2010). Traducción y asimetría. Frankfurt, Peter Lang. 